\title{
CURADORIA LITERÁRIA NO PIBID DE PORTUGUÊS DA UFRJ E COLÉGIO PEDRO II
}

\author{
Marcos Scheffel ${ }^{1}$ \\ Yandara Virginia Ribeiro Costa Moreira ${ }^{2}$
}

\begin{abstract}
RESUMO:
A escolha de obras literárias para serem lidas na escola - ou curadoria literária - é uma tarefa que pressupõe um grande poder por parte dos professores e dos sistemas de ensino (BAJOUR 2012; ANDRUETTO 2017; COLOMER 2017). Não é um gesto neutro, pois escolhemos e descartamos, dizemos se tal obra fará parte do cânone escolar ou não. Em torno da escolha de uma obra, uma série de questões aparecem para os professores: interesses dos alunos, grau de maturidade dos leitores, temas e problemas a serem discutidos, gêneros importantes na tradição escolar, recomendações de documentos oficias, currículos escolares, interesses do mercado editorial, entre outros. Em meio a tudo isto, deve-se ainda priorizar a qualidade literária e estética das obras para que os alunos tenham um contato significativo com a literatura e com a educação literária (BAJOUR 2012; ANDRUETTO 2017; COLOMER 2017). Acreditamos que a discussão de critérios para escolha de obras literárias (curadoria) é um importante saber a ser desenvolvido ao longo da formação inicial de futuros professores. Todas estas questões aqui postas foram amplamente discutidas ao longo do Programa Institucional de Bolsas de Iniciação à Docência (PIBID) na parceria que se estabeleceu entre a UFRJ e o Colégio Pedro II. Apresentamos aqui algumas considerações a respeito do tema e alguns resultados obtidos.
\end{abstract}

Palavras-chave: Pibid de Língua Portuguesa; curadoria literária; educação literária.

\begin{abstract}
:
The choice of literary works to be read at school - or literary curation - is a task that presupposes great power on the part of teachers and educational systems (BAJOUR 2012; ANDRUETTO 2017; COLOMER 2017). It is not a neutral gesture, because we choose and discard, we say whether such work will be part of the school canon or not. Around the choice of a book a series of questions arise for teachers: students' interests, degree of maturity of the readers, themes and problems to be discussed, important genres in the school tradition, recommendations of official documents, school curricula, editorial market interests, among others. In the midst of all this, the literary and aesthetic quality of the works should also be prioritized so that students have a significant contact with literature and literary education (BAJOUR 2012; ANDRUETTO 2017; COLOMER 2017). We believe that the discussion of criteria for choosing literary works (curation) is an important knowledge to be developed during the academic life of future teachers. All of these issues raised here were widely discussed throughout PIBID in the partnership that was established between UFRJ and Colégio Pedro II. Here we present some considerations on the subject and some results obtained.
\end{abstract}

Keywords: Portuguese-speaking Pibid; literary curation; literary education.

\footnotetext{
${ }^{1}$ Professor de Didática de Português e Literatura da UFRJ. Professor do ProfLetras - UFRJ. Coordenador do Pibid de Português e Literatura entre 2018 e 2020. marcosscheffel@ fe.ufrj.br

2 Professora de Português do Colégio Pedro II - Engenho Novo. Supervisora do Pibid de Português e Literaturas entre 2018 e 2020. yandaramoreira@ hotmail.com
} 


\section{Introdução}

A tarefa de escolher livros de literatura a serem adotados na escola brasileira foi, durante muito tempo, ligada às ofertas do mercado editorial e à força da tradição. No primeiro caso, podemos nos lembrar das coleções Vaga-Lume ou Para gostar de ler, que sempre vinham acompanhadas de suas fichas de leitura a serem respondidas pelos alunos. Como ambas coleções tinham vários títulos, cabia ao professor escolher o livro (ou os livros) que achava mais adequados para aquela série. Quanto à força da tradição, ela parece se manifestar mais no ensino médio, quando o professor se vê na obrigação de colocar os alunos em contato com os "grandes autores", as "grandes obras do cânone" nacional, com a história da literatura brasileira.

Os programas de leitura, tanto nacionais como estaduais, também têm cumprido um importante papel ao disponibilizar uma listagem de livros que foram lidos e avaliados com rigor por especialistas da área. O Programa Nacional da Biblioteca da Escola (PNBE), que iniciou em 1997, foi o projeto mais duradouro de aquisição de obras no Brasil e conferiu a várias obras a categoria de "altamente recomendáveis". Este selo de qualidade era cobiçado pelas editoras, independentemente das compras governamentais, pois esta classificação inseria a obra em um circuito de obras prestigiadas que serviam de referência aos interessados na leitura literária (professores, bibliotecários, secretarias de educação). O PNBE foi substituído pelo Programa Nacional do Livro Didático, PNLD-Literário, que trouxe mudanças importantes. Como no PNBE, há todo um processo de análise de cada obra por dois avaliadores (avaliação cega) e mais o trabalho de um supervisor para dirimir qualquer inconsistência destas avaliações. Os livros são apenas classificados como aptos a fazerem parte da lista de aquisição de obras e não recebem mais o selo de "altamente recomendáveis". Os avaliadores desclassificam as obras inapropriadas baseados em critérios como: não serem obras literárias (didatismo); vincularem estereótipos / preconceitos; apresentarem erros crassos de português - critérios que já eram usados no PNBE. Mas a grande mudança trazida pelo PNLD-Literário em relação ao PNBE está no papel do professor da educação básica no processo, pois agora cabe a ele a escolha, dentre as obras selecionadas, daquelas que serão enviadas para a escola. Parte-se do pressuposto de que é o professor quem pode melhor definir: o perfil dos jovens leitores, temas de interesse desses jovens, projetos que podem ser desenvolvidos, gêneros a serem trabalhados etc.

Também acreditamos que a escolha de obras literárias a serem adotadas em sala de aula deva ser sempre algo pensado pelo professor que, para isso, deve dispor de critérios de escolha 
que levem em consideração inúmeros aspectos, incluindo neles, sua experiência, suas motivações pessoais, mas principalmente a qualidade literária das obras e os efeitos que podem causar nos jovens leitores. O presente artigo procura, portanto: 1) promover uma discussão em torno da importância da escolha de obras e dos critérios de escolha (OLIVEIRA 2005; BAJOUR 2012; ANDRUETTO 2017; COLOMER 2017); 2) ver como a escolha de obras é um saber necessário aos futuros professor de português e literatura, que atuarão na Educação Básica; 3) trazer alguns resultados das discussões promovidas com os participantes do projeto por meio do Programa de Iniciação à Docência - PIBID de Português e Literatura da Universidade Federal do Rio de Janeiro (UFRJ) - no campus Engenho Novo II do Colégio Pedro II, no período de 2018 a 2019, a respeito da escolha de obras (curadoria). ${ }^{3}$

\section{A escolha de obras: um gesto de poder}

Em Ouvir nas entrelinhas - o valor da escuta nas práticas de leitura, Cecília Bajour (2012, p.27) afirma que:

A escolha de textos vigorosos, abertos, desafiadores, que não caiam na sedução simplista e demagógica, que provoquem perguntas, silêncios, imagens, gestos, rejeições e atrações, é antessala da escuta.

Para Bajour, a ideia de textos vigorosos que provoquem situações de fala e escuta sobre a literatura é o caminho para a formação de leitores. Ao narrar suas atividades na pós-graduação em Literatura Infantojuvenil na cidade de Buenos Aires, em um curso de especialização gratuito, oferecido para docentes de todos os níveis de ensino, Bajour mostra o caráter processual da escolha de obras: a necessidade do professor construir um repertório, aprender com as leituras realizadas em sala, não ter preconceitos em relação aos leitores (achar que eles não serão capazes de gostar de obras mais sofisticadas por serem pobres, por exemplo).

Este pressuposto de trazer obras que suscitem "a conversa literária" é baseado na obra Tell me - children, reading and talk, de Aidan Chambers (2011). Ao falar da escolha de obras, o autor inglês afirma que a seleção de obras, realizada por professores, para serem lidas em voz alta - deve-se destacar que o método do autor é direcionado a crianças das séries iniciais - é

\footnotetext{
${ }^{3}$ O Colégio Pedro II oferece todos os níveis da Educação Básica, desde a Educação Infantil até o Ensino Médio Regular, Técnico Integrado e Proeja. Há nove campi do CPII no Estado do Rio de Janeiro. Este artigo aborda uma experiência realizada no campus Engenho Novo II, localizado na zona norte da capital.
} 
baseada em obras que lhes são familiares e também em novas descobertas. Chambers lança, ainda, perguntas norteadoras para ajudar na escolha das obras: por que a criança precisa ler esta obra? Como esta obra vai auxiliar na leitura de outras obras no futuro? Para Chambers, a resposta não é fácil e depende de circunstâncias locais e históricas, e de particularidades das crianças. Conforme explica,

[t]odo professor deve encontrar as respostas certas para a sua situação. Isso não deve ser feito sozinho, mas em cooperação com colegas da escola e localmente. Aqui, mais uma vez, falar é a chave: enquanto negociamos as respostas para perguntas muito difíceis desse tipo, estaremos protegendo os interesses de nossos alunos da melhor forma que podemos. (CHAMBERS 2011, p.155-156. Tradução nossa). ${ }^{4}$

Além de falar desta escolha feita dentro de um grupo maior que partilha da experiência de formação de leitores, Chambers pensa em uma questão que é nuclear para Teresa Colomer (2007): o progresso do leitor. Ou seja: a escolha de uma obra deve levar em consideração conhecimentos que os leitores já têm (que lhes permite ler a obra indicada), mas também a construção de saberes que serão necessários para outras leituras que virão. O professor necessita um olhar no tempo presente - escolhendo obras que suscitem discussões relevantes, descobertas estéticas - e um olhar mais à frente, projetando competências que serão necessárias. Colomer propõe algumas aprendizagens que devem ocorrer na etapa infantil: a aquisição de sistemas de símbolos, o desenvolvimento da consciência narrativa, a ampliação da experiência, a incursão na experiência estética etc. Para Colomer, é necessário que o professor saiba "onde estão" os alunos em termos de leitura para que as obras propostas não representem "um grande salto", que pode gerar um sentimento de desalento "entre sua capacidade de fruição" [do aluno] e "a cultura proposta pela escola".

Em outra direção, María Teresa Andruetto (2017), no ensaio intitulado "Elogio da dificuldade: formar um leitor de literatura", destaca o papel dos textos que oferecem certa resistência ao leitor (os textos desafiadores, nas palavras de Bajour), pois “[c]onverter-se em leitor leva seu tempo e é uma tarefa de alta intensidade; trata-se de dar saltos sobre si mesmo até uma consciência maior, de maior complexidade [...]” (ANDRUTETTO 2017, p.94). A autora alerta para os riscos de se escolher obras simplificadoras e reforça o papel da escola de “igualador social dos recursos culturais" (2017).

\footnotetext{
${ }^{4}$ Every teacher has to find answers that are right for her situation. This should not be alone but in co-operation with colleagues at school and locally. Here again talk is the key: so long as we negotiate together the answers to very difficult questions of this kind, we are protecting the interests of our children in the best way we can. (CHAMBERS, 2011, p. 155-156).
} 
Parece-nos que todos os autores aqui citados concordam neste ponto: escolher é um gesto de poder do professor e dos sistemas educacionais e, como todo gesto de poder, deve ser exercido com responsabilidade. Não é simplesmente escolher uma obra para ocupar o tempo escolar, para dar uma nota aos alunos ou para seguir uma tradição escolar. Trata-se de escolher obras com qualidade estética (o mercado infantil e juvenil brasileiro está repleto delas), que contribuam para a formação da identidade leitora dos alunos e que tragam possibilidades de fala e de escrita significativas para a sala de aula.

\section{O professor curador}

Escolher materiais para serem levados para sala de aula é uma tarefa realizada por professores de todas as disciplinas e em qualquer nível de ensino. Mesmo quando o professor tem um material apostilado, como acontece, muitas vezes, na rede privada e em redes municipais de educação (como é o caso da cidade do Rio de Janeiro), é impossível pensar que o professor, de alguma forma, não selecione atividades que serão ou não realizadas por seus alunos. No caso dos livros didáticos de Língua Portuguesa, por exemplo, é evidente a impossibilidade de utilizar todos os materiais que são sugeridos nesses livros, o que obriga o professor a fazer escolhas. Recentemente, a escolha de materiais por professores passou a ser denominada de curadoria, termo muito associado às artes plásticas e também ao universo digital para se referir à seleção, montagem e apresentação de obras ${ }^{5}$.

Sendo uma atividade realizada de modo sistemático pelos professores, revestida de grande poder (escolher determinados textos e autores significa abdicar de outros textos e autores), a curadoria de materiais deveria ser algo mais praticado nas licenciaturas de Letras. Apesar de no campo literário a seleção de obras ser algo revestido de poder - o papel do organizador de uma antologia, geralmente um crítico / um especialista, valoriza a seleção realizada - os processos de escolha ou de curadoria pouco aparecem nas práticas dos cursos de formação de professores. Antologias de grandes editoras de poemas, de contos, de crônicas circulam nas salas de aula da graduação, mas o processo de elaboração destes materiais não é discutido. Também é comum que os professores da graduação montem polígrafos com textos de literatura ou de crítica, mas que não haja uma explicitação dos critérios que nortearam as escolhas realizadas para elaboração daqueles materiais.

\footnotetext{
${ }^{5}$ Como assinala Bhaskar (2020), o termo curadoria se espalhou para vários setores de nossa vida, não sendo mais exclusivo do campo das artes plásticas.
} 
Aqui já poderíamos pensar em uma primeira forma de se refletir sobre a curadoria: ouvir organizadores de obras falarem sobre seus critérios de seleção, de organização de materiais, de preferência por um autor em detrimento de um outro, de exclusão de determinado texto daquela antologia. Muitas vezes, os textos introdutórios destes livros explicitam esses critérios. É, portanto, no contato com e na análise crítica dos materiais que se pode construir caminhos para promover escolhas próprias.

Uma segunda forma de se refletir sobre a curadoria seria por meio de uma prática curadora por parte dos licenciandos. Esta forma esbarra no caráter pouco aplicado das disciplinas de literatura e teoria da literatura ofertadas nas licenciaturas em Letras, que não se conectam com questões ligadas à formação de leitores na educação básica, constituindo-se em disciplinas de construção de repertório (algo que é importante para a curadoria) e de reflexão crítica (que também é fundamental na curadoria), mas que não avançam no que se refere a discutir como este repertório e como estas teorias se conectam com o ensino na educação básica. Cabe pensar em mecanismos para que estes processos de escolha façam parte das metodologias de ensino das licenciaturas em Letras. Enquanto isto não acontece, discutiremos, na seguinte seção, atividades ligadas à curadoria, desenvolvidas por meio do PIBID de Língua Portuguesa da UFRJ no campus Engenho Novo II do Colégio Pedro II.

\section{Projeto Curadores}

O Projeto Curadores nasceu quando nossos encontros, entre professora de Educação Básica, supervisora do estágio supervisionado, e estudantes de Letras da UFRJ, evidenciaram dois possíveis caminhos para seguir no PIBID: aproximar os graduandos da leitura literária praticada nos anos finais do Ensino Fundamental do campus Engenho Novo II do Colégio Pedro II, localizado no subúrbio do Rio de Janeiro; e permitir que os estagiários se tornassem efetivamente atuantes nessa comunidade escolar.

Queremos dizer que, por um lado, foi preciso vencer as barreiras que afastavam os pibidianos das crianças e pré-adolescentes do Ensino Fundamental II (EFII), considerado um segmento desprestigiado pelos alunos da graduação. Grande parte dos estagiários demonstrava preferência pelo Ensino Médio (EM), queria estar em salas de aula de EM e conviver com estudantes mais próximos em idade, universo compartilhado e referências. Os pibidianos pareciam acreditar que o EM comportaria supostamente o melhor currículo ou, pelo menos, a Literatura que lhes era reconhecível, a adulta. Não seria tão arriscado dizer que, nas memórias 
escolares autobiográficas desses estagiários, a própria prática sistematizada de leitura literária estaria associada ao EM e aos estudos preparatórios para ingresso na Universidade. Os licenciandos poderiam, ainda, estar atrelados àquele equívoco de que a Literatura começa no EM (por ser o momento em que se estudam as escolas literárias, a historiografia literária).

Parte dessas barreiras foi atravessada por força da contingência: a disponibilidade desses estagiários permitiu que fossem supervisionados justamente pela professora que trabalhava exclusiva (e efusivamente!) com EFII. Inicialmente atraídos pela agenda e retraídos pelas crianças, alguns deles deram uma chance à novidade de estar no EFII.

Por outro lado, retomando um de nossos caminhos já mencionados acima, também foi necessário envolvê-los genuinamente nas atividades do estágio, para que não vinculassem o PIBID à exclusiva observação de aulas ${ }^{6}$. Muito embora observar as aulas da professora supervisora - de maneira orientada, avaliando as estratégias de ensino aprendizagem usadas tenha feito parte dessas atividades, nosso desejo era retirá-los de uma posição tão somente de observadores e vê-los em ação, refletindo de forma mais atenta sobre a formação de leitores literários.

Nesse sentido, o Projeto Curadores foi providencial. Nosso propósito final era a organização de uma coletânea de contos de terror destinada a alunos de EFII, em especial para as turmas de sétimo ano, cujo currículo acolhe e estimula essa literatura de gênero, assim chamada por apresentar, tal como as categorias policial e ficção científica, características relativamente estáveis que permitem reuni-la em um gênero.

O Projeto foi assim batizado por força da acepção comum de curadoria, que alude à ideia de seleção, de escolha. Foi Roberto Corrêa dos Santos (2013), no entanto, quem nos sensibilizou para outro sentido desse mesmo termo, mais próximo da ideia de cuidar. Na obra As palavras, Roberto Corrêa dos Santos seleciona "frases-enunciados-pensares-aparições" de diversos livros de Clarice Lispector, cuja escritura é marcada por um processo muito próprio de fazer emergir, em seus enredos, frases reveladoras de pensamentos. E, em notas de trabalho, Santos (2013) concebe o realizar curadoria ou curar textos como "deixar o tempo, ir olhando, afastar-se, retomar, prosseguir em fúria, rir muito, estremecer, borrar as folhas com grafite, surpreender-se, hesitar um pouco" (SANTOS, 2013, p. 304). Foram atos de leitura como esses que tentamos perseguir ao longo do Projeto aqui relatado.

\footnotetext{
${ }^{6}$ Denominamos "supervisor" o professor de Educação Básica que supervisionou os estagiários pibidianos na escola; e "coordenador" o professor de Ensino Superior que conduziu o subprojeto.
} 
Mais do que conhecer (de nome, como dizem...) autoras e autores que pudessem ser acessados pelo público juvenil, era preciso que os pibidianos os lessem: grifando, hesitando, rindo, surpreendendo-se, curando, tal como sugere Santos.

\section{"Escolher já significa estar lendo"}

"Um grande número de problemas daqueles que pensam sobre literatura infantil se acumula à espera de ser interpelado por uma escolha. Escolher já significa estar lendo", explica Bajour (2012, p.109). Cecilia Bajour nos ajudou a compreender que, embora tenhamos elaborado um plano de trabalho tradicional, prevendo um primeiro momento concentrado na leitura de contos de terror, seguido de análise e seleção para nossa coletânea, no decorrer da curadoria essas etapas acabaram acontecendo de forma não sequenciada. Escolher e ler, afinal, além de gestos não neutros, não se sequenciam reservados em conjuntos puros. Leiturasescolhas ou escolhas-leituras foram feitas, refeitas mais ao sabor da proliferação de ideias, decorrentes dos encontros e conversas que realizávamos, do que do rigor de uma metodologia de progressão linear. Fomos afetados por motivos diversos, em temporalidades diversas: projetos gráficos e elementos paratextuais atraentes motivavam o avanço de algumas leituras; um prefácio de um organizador de antologia nos sinalizava um critério de seleção; a discussão de um texto teórico modificava critérios e nos fazia excluir contos aparentemente já escolhidos; parágrafos introdutórios estimulantes, fator a ser levado em conta sobretudo para o leitor jovem, determinavam a manutenção do conto na coletânea; o relato de leitura empolgado feito por um dos estagiários abria espaço para uma leitura coletiva compartilhada.

Diferentemente de um organizador contratado por uma editora para compilar contos, a nossa experiência foi profundamente coletiva, envolveu uma comunidade de leitores bastante heterogênea, que incluía estagiários, pouco familiarizados com o gênero terror, e os próprios alunos de EFII, em sua maioria arrebatados pelo universo de medo e suspense que submetemos ao seu crivo.

Isso se manifestou de modo mais concreto quando realizamos uma votação nas turmas de sétimo ano, após conhecerem brevemente a proposta do Projeto Curadores. O Projeto lhes foi apresentado pelos próprios pibidianos, em uma aula realizada na biblioteca, que incluiu o convívio dos alunos com o acervo de coletâneas do Projeto (a maloteca) e o uso de slides sobre coletâneas de terror. No final dessa aula, que também foi a culminância de uma extensa sequência didática com os contos da obra Sete ossos e uma maldição (2006), de Rosa Amanda 
Strausz, cada aluno deveria escolher e anotar num papel sua narrativa preferida do livro. O conto mais votado ganharia espaço na coletânea final do Projeto Curadores. Ou seja, convidamos os alunos de sétimo ano a também atuarem como curadores, já que eles foram leitores da mencionada coletânea de Strausz.

As imagens 1 e 2 a seguir registram esses momentos: a aula interativa na biblioteca, em que a maloteca (mais à frente, relatamos o que significou esse recurso) ocupa o centro do espaço e foi acessada livremente pelos alunos; e uma das reuniões com os estagiários, em que foi feita a contagem de votos dos alunos:

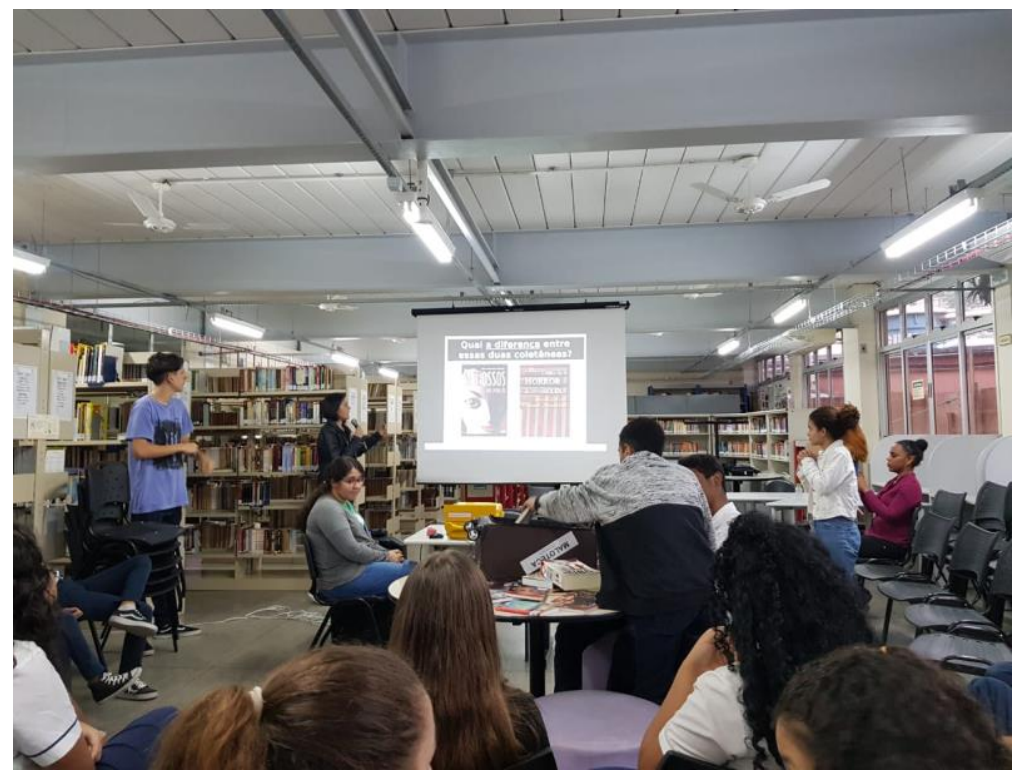

Imagem 1- Aula ministrada pelos estagiários, na biblioteca do campus Engenho Novo II do Colégio Pedro II, sobre coletâneas de terror ${ }^{7}$

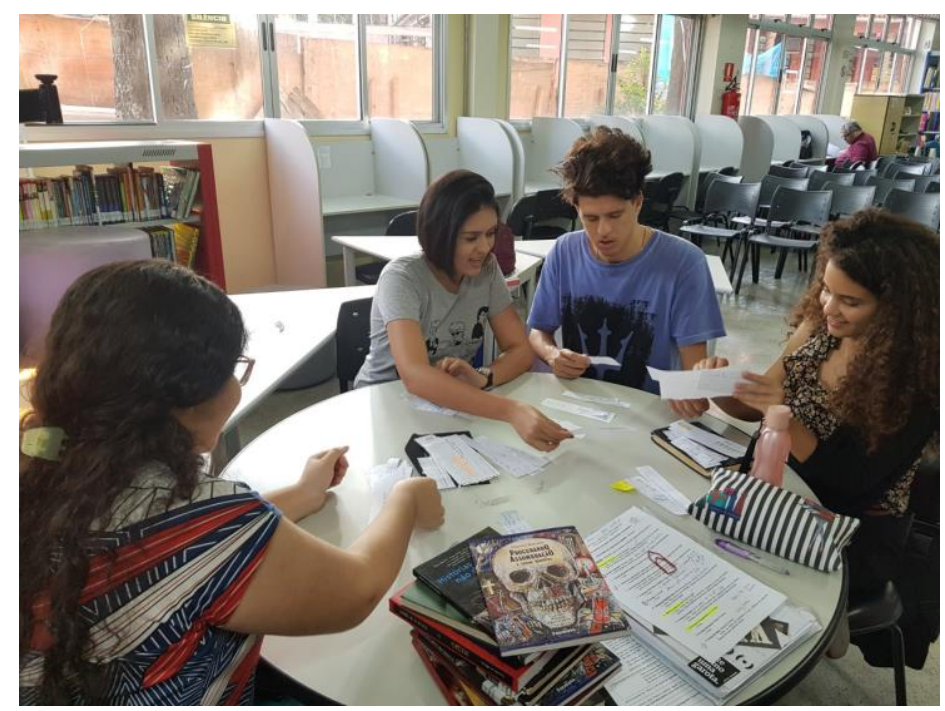

\footnotetext{
${ }^{7}$ Os autores do trabalho declaram possuir autorização para utilização de todas as imagens presentes no artigo.
} 
Imagem 2- Reunião do Projeto Curadores, realizada no setor juvenil da biblioteca do campus Engenho Novo II do Colégio Pedro II

Sete ossos e um maldição (STRAUSZ, 2006), vale ressaltar, adotado para leitura literária de um dos trimestres letivos, integrou de maneira peculiar o acervo consultado pelo Projeto, dispondo-se como coletânea exemplar. Por contemplar vários critérios da nossa curadoria - entre os quais destacamos a qualidade literária, a verossimilhança na construção dos diálogos, a construção de inícios e finais instigantes, a adequação à competência do leitor -, praticamente todos os contos lidos e discutidos entre os curadores eram explicitamente comparados aos de Strausz.

Era imprescindível, no entanto, promover o acesso dos universitários a outras (e muitas) coletâneas já existentes no mercado dedicadas ao terror e ao leitor jovem (consultamos, também, compilações adultas em que avaliamos a mudança de destinatário). Forçar essa convivência requisitou formação do nosso acervo, que apelidamos "maloteca". Era literalmente uma mala, preenchida de coletâneas de contos à disposição dos pibidianos para consulta e empréstimo.

As imagens 3 e 4 não apenas registram a existência da maloteca, mas também testemunham um dos obstáculos que enfrentamos no decorrer do Projeto: a biblioteca da escola não autorizava empréstimos de livros diretamente aos estagiários. A maloteca, então, permitiu reunir e disponibilizar aos pibidianos coletâneas de várias procedências (obras da biblioteca, emprestadas à professora supervisora; outras trazidas pelos próprios estagiários, que trocaram entre si; algumas pertenciam à professora supervisora e a outros professores do campus ENII).
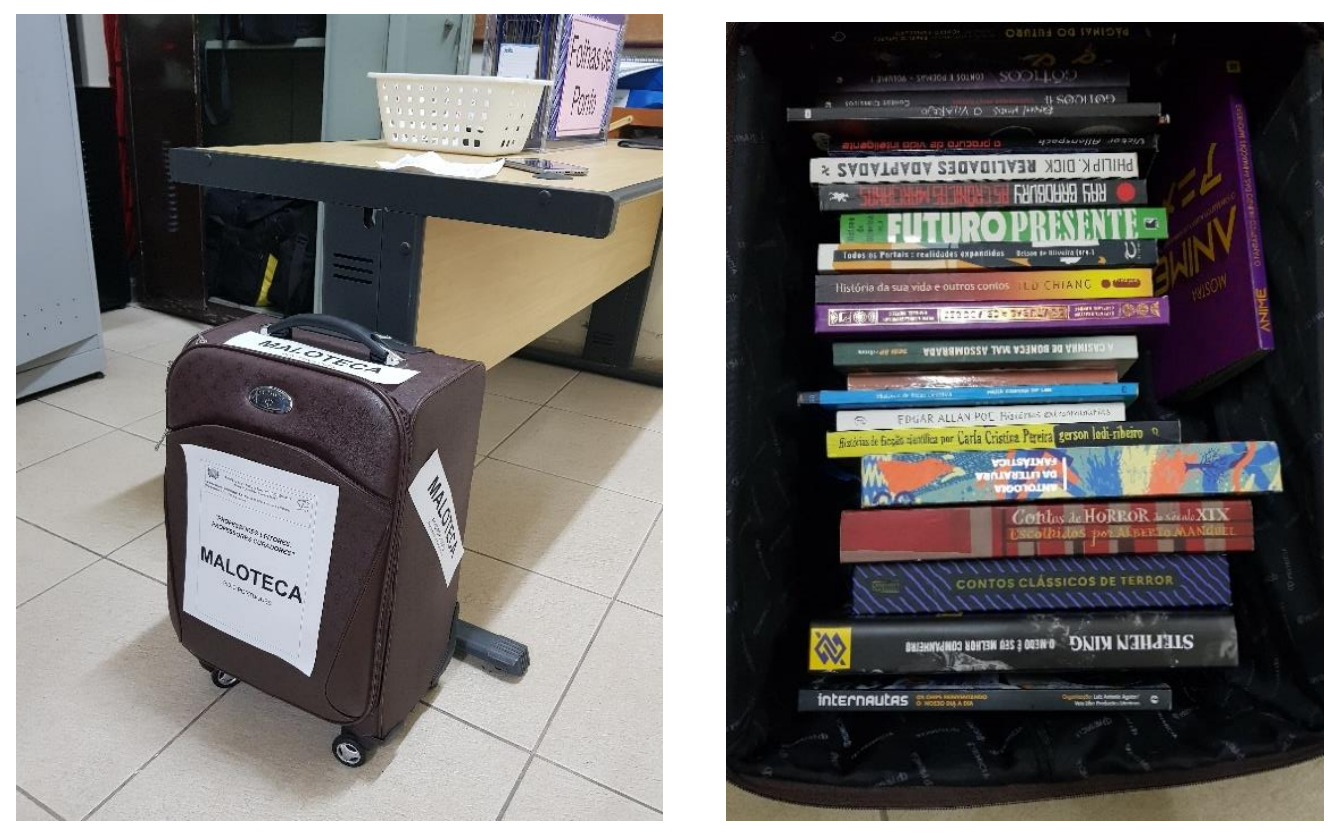
Imagens 3 e 4 - Acervo de coletâneas de contos, a maloteca, hospedada na sala de professores do campus ENII

O gênero escolhido levou aos pibidianos tanto autores e obras que, a princípio, poderíamos supor serem os mais óbvios, como Edgar Allan Poe e Stephen King, e outros que representaram plena novidade, como a já citada Rosa Amanda Strausz, mas também Rosana Rios, Flavia Muniz, Shirley Souza, Helena Gomes. Não por acaso, foram unanimemente desconhecidas justo as autoras dedicadas ao público jovem, o que demonstra o distanciamento dos graduandos em relação à literatura juvenil.

O desafio foi apresentar um volume grande de novidade simultaneamente ao próprio amadurecimento das leituras. Para alguns, tudo foi novidade:

\begin{abstract}
Hoje foi um dia bem produtivo no colégio. Primeiro assistimos a aula do $7^{\circ}$ ano, turma 702. A professora Yandara trabalhou com a turma um conto chamado "O Coração delator" do autor Edgar Allan Poe. Nunca tinha ouvido falar do Edgar e acredito que não poderia ter conhecido de forma melhor, pois percebi que foi experiência muito legal tanto para mim quanto para as crianças da turma.

Confesso que fiquei impressionada com a escrita do autor e inclusive já pedi emprestado alguns livros dele! (Pibidiano 1) . $^{8}$
\end{abstract}

Esse depoimento, recolhido pelos professores universitários, coordenadores do PIBID, nos daria espaço para amplas reflexões a respeito da trajetória desse pibidiano como leitor literário, desde a Educação Básica até o momento acadêmico atual, na tentativa de investigarmos quais fatores o afastaram até mesmo de ouvir falar de Edgar Allan Poe.

Celebramos que, por ocasião do estágio e do Projeto, Poe tenha passado a fazer parte de seu percurso, fortalecendo nossa comunidade de leitores. Alunos, pibidianos e professora supervisora, convidados pela literatura de Poe a construir leituras complexas, certamente levarão consigo marcas dessa experiência singular.

Compartilhamos mais alguns depoimentos que aludem ao encontro com Poe:

Li vorazmente quantos contos eu pude, começando pelo obrigatório Edgar Allan Poe. Dessa vez, porém, a minha leitura é diferente de todas que eu já fiz. Leio pensando nas crianças, em como elas vão receber aquele texto, ou no quanto aquele texto pode ser proveitoso em aula ou nos materiais didáticos que posso desenvolver e as discussões que posso estimular. É realmente um olhar novo que tenho desenvolvido, e que a universidade não nos oferece. É o olhar da prática pedagógica. É o momento de viver a realidade da escola. Poder ser uma das autoras deste projeto tem sido uma experiência incrível e seguramente estou aprendendo muitas coisas que, num futuro não muito distante, certamente usarei como uma profissional da educação. (Pibidiano 2).

\footnotetext{
${ }^{8}$ Os relatos dos pibidianos foram feitos em Diário escrito ao longo do PIBID e se constituíram em importante documento para podermos acompanhar o processo formativo dos envolvidos. Ao ingressar no programa os bolsistas assinam termo de cessão de materiais produzidos, bem como de suas imagens (fotos).
} 
Poe é Poe. Hoje, no sétimo ano, a Yandara leu o conto "O coração delator" ("The Tell-Tale Heart”, de Edgar Allan Poe, que está entre meus autores favoritos). A aula foi especial por dois motivos: o primeiro (e mais óbvio) é ter o prazer de reler com as "crianças" uma história de um escritor que eu admiro e, com isso, me dar conta de aspectos do texto que, antes, haviam passado despercebidos; e, em segundo lugar, porque, dias atrás, quando procurava na biblioteca da faculdade uma antologia do POEta, tive um achado incrível: um livro raro da Penguin que traz todos os contos, todos os POEmas e ainda análises literárias feitas pelo próprio autor. E o melhor: em inglês. Wonderful! (Pibidiano 2).

Além do evidente estímulo à leitura literária que o Projeto promoveu, acreditamos que, ao acompanharem esse trabalho com o conto "O coração delator", de Edgar Allan Poe, muitos pibidianos puderam ampliar suas habilidades como curadores porque passaram a qualificar a noção de desafio - termo, aliás, tão corrente nos ambientes escolares que parece justificar, na vagueza do senso comum, a pronta desistência de adoção de determinados textos e autores ou a cega adesão a formas de leitura limitadas ao par autor-e-obra.

Reconhecemos ser um desafio ler contos de Poe em turmas de sétimo ano, mas é preciso identificar os fatores que o compõem - a complexidade léxica, a contextualização da narrativa em tempos remotos, a extensão, a dificuldade de acesso a edições ilustradas vendidas por preços altos -, e, enfim, criar outras formas de ler textos mais complexos com os alunos da Educação Básica.

Se estávamos concentrados na literatura de terror, tão apreciada pelo público juvenil, não poderíamos deixar de apresentar a esses leitores em formação contos considerados adultos, difíceis, desafiadores, mas também de alta qualidade literária e paradigmáticos do gênero ${ }^{9}$. Nesse sentido, para compor a coletânea de nosso Projeto, nos incumbimos de abrir mundos e repudiar possíveis manifestações do que Cecilia Bajour chama de "teoria do déficit":

Muitos que acreditam nisso designam como 'carência de conhecimentos prévios' a falta de um suposto arcabouço cultural e educacional de que padecem cada vez mais as crianças de nossos países. Conhecimentos prévios que só seriam patrimônio de uma pequena parcela de privilegiados e que só são concebidos como possíveis se associados à escolaridade e ao acesso a determinados bens culturais, quase nunca com a vida real, a vida que se pode levar ou pela qual se luta (BAJOUR, 2012, p. 113).

Prescindir desses desafios, porque os adolescentes supostamente não teriam maturidade cognitiva ou conhecimentos prévios suficientes, pode resultar em um reforço da concentração do saber, implicado nesse texto literário, nas mãos de uma elite. Conforme também preconiza João Wanderlei Geraldi (2021), o acesso a bens culturais dos campos da literatura e das artes

\footnotetext{
${ }^{9}$ Segundo Colomer (2007), um bom corpus de leitura para crianças e jovens é formado por obras bastante distintas que ajudam os alunos a assimilarem padrões literários, mas que também ajudam a reforçar sua autoimagem de leitores.
} 
deve ser priorizado na seleção que necessariamente a escola faz dos gêneros discursivos que integram o programa de ensino.

\section{Os critérios de Curadoria e o resultado}

Pensar a respeito dos critérios, amplos e complexos, que foram mobilizados na escolha dos contos, foi tarefa que se deu concomitantemente à leitura dos contos e à vivência de um trimestre letivo dedicado ao terror como gênero literário, nas turmas de sétimo ano. Ou seja, o Projeto se desenvolveu com revisão bibliográfica - composta por referenciais especializados no tema da leitura literária na escola e da curadoria - e também com aplicação empírica de sequências didáticas centralizadas em leitura de contos de terror em turmas de sétimo ano do EFII.

Pudemos experimentar em sala de aula a potencialidade de alguns contos préselecionados, propondo aos alunos, oralmente e/ou na forma de exercícios, questões que estimulavam a formulação de hipóteses de leitura, e observar os critérios de curadoria do Projeto. Aliamos o que estudávamos com o que se apresentava nas reações concretas do grupo de adolescentes.

Acolhemos, em grande medida, os critérios de avaliação e seleção de livros infantis e juvenis propostos por Teresa Colomer, principal referência do nosso Projeto, em sua obra Introdução à literatura infantil e juvenil atual (2017). A “qualidade dos livros", para a pesquisadora, é parâmetro primordial. Nesse quesito, Colomer (2017) ressalta que não há fórmulas prontas para definir se um livro ou outro é capaz de oferecer uma experiência literária de qualidade: "não há mais segredo, pois, para este aspecto da seleção, que o de ser um bom leitor e contrastar a leitura dos livros infantis, em primeiro lugar, com o interesse e prazer que proporcionam ao mesmo adulto" (2017, p. 254). Esse juízo imediato, que os estagiários expressavam a partir da leitura dos contos, se manifestou muito rapidamente em nossas conversas.

Tivemos a oportunidade de refinar esse juízo imediato, quando analisamos os contos de acordo com o trabalho realizado pelo autor com a linguagem, levando em conta "a riqueza, precisão e qualidade das imagens da linguagem utilizada, atendendo à 'paleta de cores' de um texto que não se propõe simplesmente a informar sobre um acontecimento" (COLOMER, 2017, p. 256). Nossa atenção se voltou para a "textura das palavras" (COLOMER, 2017, p. 256), e não exclusivamente para a progressão da trama cujo clímax proporcionasse susto ou medo. 
Outro critério de seleção e análise dos contos também se estabeleceu quanto à verossimilhança na construção dos diálogos. Sobretudo quando os personagens eram adolescentes, observamos que se manifestassem sem artificializações excessivas ou em falas que não parecessem ideias adultas verbalizadas por um jovem.

Aplicamos, ainda, o critério da análise do início e do final da narrativa. Como começa o conto de terror foi um fator que entendemos como uma isca, que poderia não apenas contribuir para instaurar o clima típico (a ambiência) desse gênero, mas também seduzir os leitores jovens a continuar a leitura. E como termina a narrativa foi fator que levamos em conta em sua potencialidade de surpreender, pela escolha por revelar ou não o elemento sobrenatural ou por evidenciar alguma monstruosidade humana. Destacamos, sobre esse parâmetro, a escolha certeira do conto "O travesseiro de plumas", de Horacio Quiroga (QUIROGA, 2013). O final da narrativa, lida integralmente em sala de aula, gerou reações muito efusivas e mobilizou os alunos na discussão do enredo. Alguns mostraram-se muito surpresos com o desenlace, porque esperavam que a causa da morte da protagonista estivesse atrelada ao comportamento estranho de seu esposo, cogitado até como um vampiro; outros alunos ficaram assustados com a possibilidade de realmente existir o parasita sugador de sangue medonho que se revela no fim do conto.

A adequação à competência do leitor também foi critério atuante em nossas decisões. Os contos candidatos à nossa aprovação precisavam dispor de uma quantidade de informação possível de ser concatenada pelo adolescente em sua capacidade leitora. Um dos contos aventados, "A casa de Adela" (ENRIQUEZ, 2017), da escritora argentina Mariana Enriquez, presente na antologia As coisas que perdemos no fogo, foi excluído da nossa curadoria por esse quesito.

A princípio, uma menina que some enquanto explora com seus amigos uma casa decrépita parecia um exemplar bem escrito dos clichês do gênero. A narrativa, no entanto, se complica simultaneamente no nível da história e do discurso. Uma das integrantes do grupo de Adela, já adulta e carregada de melancolia, é quem narra o ocorrido em forma de memórias da pré-adolescência, criando saltos cronológicos; essa narradora recupera o suicídio trágico de seu irmão e melhor amigo de Adela e deixa o final em aberto pela falta de explicação para o sumiço de Adela, ao qual muitos críticos atribuem a relação metafórica com práticas de roubo de filhos de inimigos do regime ditatorial argentino.

Embora seja rico em sua linguagem e remeta ao universo da adolescência, a abordagem adulta para a morte, em sua delicada manifestação do suicídio e do desaparecimento 
inexplicável, inflaciona o nível de angústia do conto, tornando-o inapropriado aos interesses do leitor jovem, que poderia não se sentir acolhido em seu estágio de letramento literário diante de tantas e complexas informações a serem relacionadas.

Sugerimos em substituição, na mesma linha temática da exploração curiosa de uma casa abandonada, contos como "Abbie" (BARCELOS, 2017), de Marcus Barcelos, presente na coletânea Mundos Paralelos e "A pipa que pendia no beiral”, de Hedjan C. S. (2019), integrante da antologia Gótico suburbano. Ambos disputaram nossa atenção, mas se tornaram opções excludentes por tratarem do mesmo tema.

Fizemos esforços para inovar, evitando repetir temas, espaços das narrativas e não reprisando excessivamente contos que estão presentes em várias coletâneas já existentes no mercado. Sucumbimos, no entanto, na escolha do "conto mais antologiado da literatura de horror, em todos os tempos" (MANGUEL, 2005, p. 13), segundo afirma Alberto Manguel, organizador da obra Contos de horror do século XIX. O conto "A mão do macaco", de W. W. Jacobs (JACOBS, 2005), aparece em nosso elenco - e em tantas outras antologias - por seu mérito de atração do leitor e por contemplar os critérios que já detalhamos anteriormente.

O nosso empenho em diversificar nacionalidade, gênero e raça dos autores, além da mescla entre clássicos e atuais, também favoreceu no quesito inovação, resultando em um processo de curadoria que, sobretudo por refletir uma criação coletiva, se propôs, identificou e atravessou diversos desafios.

Após muitos encontros e conversas, os curadores chegamos a este elenco de contos de terror:

O travesseiro de penas, Horacio Quiroga (QUIROGA, 2013)

Venha ver o pôr-do-sol, Lygia Fagundes Teles (TELLES, 2018)

A máscara da morte vermelha, Edgar Allan Poe (POE, 2010)

Crianças à venda: tratar aqui, Rosa Amanda Strausz (STRAUSZ, 2006)

Que sofram as criancinhas, Stephen King (KING, 2013)

A mão do macaco, W. W. Jacobs (JACOBS, 2005)

O fantasma inexperiente, H. G. Wells (WELLS, 2016)

O roedor de ossos, Rubem Fonseca (FONSECA, 2015)

A pipa que pendia no beiral, Hedjan C. S. (HEDJAN, 2019).

História de Mapinguary, Yaguarê Yamã (YAMÃ, 2012)

Laila, Shirley Souza (SOUZA, 2013)

Grota funda, Conceição Evaristo (EVARISTO, 2017)

A ilha, Heloisa Seixas (SEIXAS, 2006) 


\section{Considerações finais}

A escolha do texto que vai motivar e centralizar qualquer aula de Língua Portuguesa assume papel de destaque no planejamento didático. É o mesmo quando se trata de Literatura e se prioriza a formação literária dos estudantes: a escolha do texto literário vai oferecer, a partir de sua linguagem particular, uma cartografia que aponta possíveis caminhos ou mediações a serem realizadas, desde o trabalho prévio ou a motivação para a leitura, passando pela leitura e os mecanismos de processamento do texto propriamente dito, até as tarefas após a leitura. Ainda que não se cumpram sempre tais etapas - pré-leitura, leitura, pós-leitura (BRAGA; SILVESTRE, 2002) -, sob o risco de enrijecimento metodológico, incompatível com a Literatura, essa escolha vai, enfim, determinar a qualidade de uma experiência para indivíduos que vivem suas adolescências uma única e singular vez e podem se constituir, com nosso auxílio, como leitores literários nessa travessia.

A responsabilidade da curadoria, portanto, não é pequena e não deve ser assumida exclusivamente pela nossa intuição (embora dela nunca prescindamos). A importância de desenvolvermos habilidades como curadores literários o mais precocemente em nossa formação docente ficou evidente nas atividades do PIBID aqui relatadas. Pudemos, admitindo distintos níveis de letramento literário, nos fortalecer como comunidade de leitores, que, muito embora tenha expirado em sua formação original pelo término do estágio, deixou gravado em todos os envolvidos sua lógica catalisadora: há que se formar novas comunidades, entre colegas, estagiários, alunos, professores, bibliotecários...

Essas habilidades estarão intrinsecamente vinculadas à consistência de nossa trajetória como leitores literários - muitas vezes interrompida ou atabalhoada na roda viva da rotina profissional e suas graves limitações no cenário nacional. Só há (futuros) professores curadores entre eternos professores leitores.

\section{Referências:}

ANDRUETTO, María Teresa. A leitura, outra revolução. Tradução Newton Cunha. São Paulo: Editora do Sesc, 2017.

BAJOUR, Cecília. Ouvir nas entrelinhas - o valor da escuta nas práticas de leitura. Tradução Alexandre Morales. São Paulo: Editora Pulo do Gato, 2012. 
BHASKAR, Michael. Curadoria - o poder da seleção no mundo do excesso. Tradução Érico Assis. São Paulo: Editora do Sesc, 2020.

BRAGA, Regina Maria; SILVESTRE, Maria de Fátima Barros. Construindo o leitor competente: Atividades de leitura interativa para a sala de aula. São Paulo: Peirópolis, 2002 .

CHAMBERS, Aidan. Tell me - children, reading and talk \& The reading environment - how adults help children enjoy books. The Timble Press, Woodchester (UK), 2011.

COLOMER, Teresa. Andar entre livros - a leitura literária na escola. Tradução Laura Sandroni. São Paulo: Global, 2007.

Introdução à literatura infantil e juvenil atual. Tradução Laura Sandroni. São Paulo: Editora Global, 2017.

SOUZA, Shirley. "Laila". In: DRUMMOND, Regina; FILHO, Manuel; MUNIZ, Flávia; SOUZA, Shirley. Ilustração Camila Torrano. Lobisomem e outros seres da escuridão. São Paulo: Panda Books, 2013, (Coleção Hora do Medo, 4), p. 93-103.

ENRIQUEZ, Mariana. “A casa de Adela”. In: As coisas que perdemos no fogo. Tradução José Geraldo Couto. Rio de Janeiro: Intríseca, 2017, p. 61-75.

EVARISTO, Conceição. “Grota funda". In: Histórias de leves enganos e parecenças. Rio de Janeiro: Malê, 2017.

FONSECA, Rubem. Histórias Curtas. Rio de Janeiro: Nova Fronteira, 2015.

GERALDI, João Wanderley. A produção dos diferentes letramentos. Disponível em: https://revistas.pucsp.br/index.php/bakhtiniana/article/view/19443. Acesso em: 07 mar.2021.

HEDJAN, C. S. “A pipa que pendia no beiral”. In: Gótico suburbano. Rio de Janeiro: Luva Editora, 2019, p. 18-24.

KING, Stephen. Pesadelos e paisagens noturnas: volume 1. Tradução M.H.C. Côrtes. Rio de Janeiro: Objetiva, 2013.

MANGUEL, Alberto (Org.). Contos de horror do século XIX. São Paulo: Companhia das Letras, 2005.

JACOBS, W. W. “A mão do macaco" In: MANGUEL, Alberto (Org.). Contos de horror do século XIX. São Paulo: Companhia das Letras, 2005, p.14-24.

POE, Edgar Allan. “A máscara da morte vermelha”. In: Histórias extraordinárias. Tradução 
Antonio Carlos Vilela. Ilustrações Poly Bernatene. São Paulo: Melhoramentos, 2010, p. 7-25.

WELLS, H. G. "O fantasma inexperiente". In: PRIETO, Heloisa; SCATOLIN, Victor (Orgs.) A casinha de boneca mal-assombrada e outras histórias inexplicáveis. São Paulo: SESI-SP Editora, 2016, p. 49-72.

QUIROGA, Horacio. "O travesseiro de plumas". In: Contos de amor, de loucura e de morte. Tradução John Lionel O’Kuinghttons Rodríguez. São Paulo: Hedra, 2013, p. 114-119.

BARCELOS, Marcus. “Abbie”. In: SALI, Felipe (Org.). Mundos Paralelos. São Paulo: Abril, 2017, p. 100-119.

SANTOS, Roberto Corrêa dos (Org.). As palavras. Rio de Janeiro: Rocco, 2013.

SEIXAS, Heloisa. Frenesi: histórias de duplo terror. Ilustração Ricardo Cunha Lima. Rio de Janeiro: Rocco, 2006.

STRAUSZ, Rosa Amanda. Sete ossos e uma maldição. Rio de Janeiro: Rocco, 2006.

TELLES, Lygia Fagundes. "Venha ver o pôr do sol". In: JEHA, Julio (Org.) Contos clássicos de terror. São Paulo: Companhia das Letras, 2018, p. 349-360.

YAMÃ, Yaguarê. "História de Mapinguary”. In: Contos da floresta. Ilustração Luana Geiger. São Paulo: Peirópolis, 2012, p. 27-35. 